\title{
Çağdaş Yaklaşımlar Çerçevesinde Kamuda İnsan Kaynakları Yönetiminin Örgütlenmesi
}

\author{
Organization of Human Resources Management in The Public in The Framework of Contemporary \\ Approaches
}

\section{Recep REHIMLI}

Doç. Dr.,

Azerbaycan Cumhurbaşkanlı̆̆ına bağlı Devlet İdarecilik Akademisi, rehimli@yahoo.com

https://orcid.org/0000-0003-1414-0031

\section{Elnur ALIYEV}

Dr., Azerbaycan Cumhurbaşkanlı̆̆ına bağlı Devlet İdarecilik Akademisi ealiyev7@gmail.com

https://orcid.org/0000-0003-4440-9118
Makale Başvuru Tarihi / Received: 17.11.2018

Makale Kabul Tarihi / Accepted: 15.03.2019

Makale Türü / Article Type: Araştırma Makalesi
Anahtar
Kelimeler:

Insan Kaynakları Yönetimi,

Kamu Personeli,

Reform,

Kamuda Örgütlenme,

Kurumsallaşma,

Keywords:

Human Resources Management,

Public Servants,

Reform,

Public Organization,

\section{ÖZET}

Kamu yönetiminde insan kaynaklarının yönetiminin yeniden örgütlenmesi için yapılacak çalışmalarda öncelikle kamu hizmeti, kamuda örgütlenme ve insan kaynaklar konularının bir bütünlük içerisinde ele alınması gerekmektedir. Son dönemde gelişmiş ülkelerde gerçekleştirilen reformlar kapsamında; insan kaynakları yönetiminden sorumlu merkezi ofislerin, genel olarak insan kaynakları yönetimi konusunda ayrıntılı merkezi kontrolleri ve diğer bürokratik işlemleri azaltıp ilke, standart ve kanuni düzenlemelerin hazırlanması, performans yönetimi, insan kaynakları bilgi sistemlerinin kurulması, strateji geliştirme, üst düzey yöneticilerin seçimi gibi insan kaynakları alanında daha özellikli hususlara odaklanma eğiliminde oldukları görülmektedir. Bu noktada, makalede kamuda insan kaynakları yönetiminin teşkilatlanması, rolü ve fonksiyonları çağdaş yaklaşımlar çerçevesinde incelenmektedir.

Institutionalization,

\begin{abstract}
In order to reorganize the management of human resources in public administration in studies, primarily subjects of public service, public organization and human resources issues should be handled in an integrated manner. Within the scope of recent reforms in developed countries; human resources management in central offices responsible for human resources management generally reduce extensive centralized control and other bureaucratic procedures, It appears that they tend to focus on more specific issues in the field of human resources suc as: preparation of principles, standards and legal regulations, performance management, establishment of human resources information systems, strategy development, selection of senior executives. In this article, the organization, role and functions of human resources management in public administration were examined in the context of modern approaches.
\end{abstract}




\section{GIRISS}

Herhangi bir devlet tarafından sağlanan kamu hizmetleri, o ülkedeki kamu politikalarının kalitesiyle yakından ilişkilidir. Günümüzde kamu hizmetlerinin en ideal şekilde nasıl gerçekleştirileceği, kamu hizmetini ifa edecek kişilerde aranacak niteliklerin neler olacağ belirleneceği, nasıl çalıştırılacağı, ne şekilde denetlenecekleri, görevlerini yaparken hangi temel ilkelere/değerlere bağlı olacakları, görevleri ile ilgili ödev, hak, yetki ve sorumluluklarının nasıl düzenleneceği ve neler olacalacağı gibi hususlar kamu personeli sorununun temelini oluşturmaktadır (Tutum, 1990:32).

Kamu hizmetlerinin gerçekleştirilebilmesi için kamu politikalarının oluşturulması tek başına yeterli değildir. $\mathrm{Bu}$ politikaların hayata geçirilebilmesi için demirbaşa, finansal ve işgücü kaynaklarına da ihtiyaç duyulmaktadır. Dolayısıyla da bu kaynakların en iyi şekilde yönetilmesi gerekmektedir. İşgücü yönetimi yani insan kaynakları yönetiminde; iş analizi, işgücü planlaması, işe alma (seçim), kariyer geliştirme, liyakat sistemi, performans yönetimi ve disiplin uygulamaları hayata geçirilmektedir. İnsan kaynakları yönetiminin başarılı bir şekilde uygulanabilmesi için bu alanda mevcut olan hukuk normlarına, ilkelere, işgücü piyasası uygulamalarına ve bilimsel gelişmelere bağlı kalınmalıdır. Örneğin işgücü planlamasının, istihdam edilecek personel sayısı ve personel maliyetleri ile işler için ihtiyaç duyulan yetenek ve becerilerin tespitini kapsayacak şekilde yapılması tutarlı politikaların tanımlanması açısından büyük önem taşımaktadır (OECD/IDB, 2016:102).

\section{KAMU HIZMETLERINIIN KAPSAMI}

Bir ülkedeki hizmet üretimi "kamu sektörü" ve "özel sektör" tarafından gerçekleştirilir. Bu bağlamda özel sektör faaliyetleri, özel yarar ekseninde kendi menfaatlerini maksimize etme üzerine şekillenir. Kamu sektörünce yürütülen kamu hizmetleri ise toplumun ortak amaçlarını karşılamak amacıyla kamu yararının maksimize edilmesi istikametinde gerçekleştirilir. Kamu sektörünce etkin bir kamu hizmetinin sunulabilmesi için bu sektörün (kamu idareleri ve kurumları) örgütlenmesi ve aynı zamanda da yönetimle ilgili yeni nesil yaklaşımların (government innovation) hayata geçirilmesi gerekmektedir. Bu sebeple her ülke kendi anayasal düzeni ve ihtiyaçları düzeyinde kamu sektöründe örgütsel yapısını tesis eder. Örneğin Azerbaycan'da 13 Temmuz 2012 tarihli kararname ile Azerbaycan Cumhurbaşkanı nezdinde "Vatandaşlara Hizmet ve Sosyal Yenilikler Ajansı" kurulmuştur. Faaliyet yönergelerine göre bu Ajansın kuruluş amacı ve temel görevleri; Azerbaycan'da ASAN hizmet merkezlerinin birleşik yönetiminin sağlanması, hizmet merkezlerinde faaliyet gösteren devlet kurumlarının faaliyetlerinin koordinasyonu, izleme ve değerlendirme faaliyetlerinin gerçekleştirilmesi, devlet kuruluşlarının bilgi merkezlerinin karşılıklı entegrasyonu, elektronik hizmetlerin organizasyonu sürecin hızlanmasının teşvik edilmesi, bu alandaki yönetim sisteminin geliştirilmesi olarak tanımlanmıştır.

Yönetim biliminin temel unsurlarından olan "örgütlenme", belirli bir amaç doğrultusunda mal ve hizmet üretimi gibi fiziki etkinlikler ile işin kısımlara bölünmesi ve fert - küme ilişkilerini esas almaktadır. Örgütsel yapı içerisindeki otorite ve kişiler arasında hiyerarşik bir yapının kurulması ve iş bölümünün tesis edilmesi örgütlenmenin temelini oluşturur. İşin belirli kısımlara ayrılması ile çalışanlar arasında iş bölümü ve uzmanlaşmaya gidilmesi aynı zamanda bölümler arasında bir koordinasyon ihtiyacını ortaya çıkarmaktadır. Örgüt kuramının kamu yönetimine uygulanması çerçevesinde, siyasi otoritenin ortaya koyduğu politikalar doğrultusunda kamu hizmetlerinin hayata geçirilebilmesi amacıyla bir örgütsel yapılanmaya ihtiyaç duyulmaktadır. Sonrasında ise bu örgütlenme içerisinde istihdam edilecek kamu görevlilerinin hukuki statüleri, nitelikleri, ödev, hak ve yükümlülüklerinin ortaya konulması gerekmektedir. Bu durum, sunulacak kamu hizmetleri ve bu sunumu gerçekleştiricek teşkilatlanmanın insan kaynakları yönetimi anlayışı ile birlikte değerlendirilmesini zorunlu kılmaktadır.

Bir devletin ürettiği kamu hizmetlerinin kapsam ve içeriği, sahip olduğu mali imkanlar ile kamu hizmetlerinin hayata geçirilmesinde üstlendiği rol ve fonksiyonlarında "müdahaleci-Keynesyen" veya "neo-liberaldüzenleyici" yaklaşımlardan hangisini tercih ettiği ile yakından ilişkilidir. Yani devletin ekonomi ve toplumdaki genel ağırlığı ile üstlendiği rol ve fonksiyonlar sunduğu kamu hizmetlerinin kapsamını belirlemektedir. Bu sebeple tercih edilen yaklaşım ve kabullere bağlı olarak sunulan kamu hizmetlerinin kapsamı ülkeden ülkeye değişmektedir. Ancak bazı farklılıklar söz konusu olsa da kamu hizmetlerinin genel çerçevesinde küresel çapta genel bir uzlaşma söz konusudur. BM tarafından temel devlet fonksiyonlarına ilişkin genel çerçeve ortaya konulmuştur. 
Tablo 1. COFOG Devlet Fonksiyonlarının Sinıflaması

\begin{tabular}{|c|}
\hline Genel Kamu Hizmetleri \\
\hline Kamu Düzeni ve Güvenlik Hizmetleri \\
\hline Savunma Hizmetleri \\
\hline Sosyal Güvenlik ve Sosyal Yardım Hizmetleri \\
\hline Ekonomik İşler ve Hizmetler \\
\hline Çevre Koruma Hizmetleri \\
\hline İskan ve Toplum Refahı Hizmetleri \\
\hline Dinlenme, Kültür ve Din Hizmetleri \\
\hline Eğitim Hizmetleri \\
\hline Sağlık Hizmetleri \\
\hline
\end{tabular}

Kaynak: European Commission, 2011

Kamu sektörü tarafından yürütülecek bu hizmetlerin üretimi için kullanılacak beşeri kaynakların da bu alanlara yönlendirilmesi, bunlar arasında önceliklendirmenin yapılması gerekmektedir. Hizmetlerin önceliğine göre, ilgili alana aktarılacak insan kaynaklarının niteliği, sayısı, istihdam şekilleri ve mali hakları farklılaşacaktır.

Devlet, amaçları bağlamında genel kamu hizmetleri, savunma, güvenlik ve adalet hizmetleri gibi tam kamusal nitelikli hizmetlerini devlet memurları eliyle yürütmektedir. Sosyal koruma, çevre, eğitim, sağlık ve benzeri nitelikteki kamusal mal ve hizmetlerin sunumunda tercih edilen istihdam şekli ise ülkeden ülkeye değişmektedir. Mülkiyeti kamu sektörüne ait olan ve piyasa için ekonomik nitelikte mal ve hizmet üreten iktisadi teşekküllerde istihdam edilen kişiler özel sektör koşullarında ve işçi statüsünde çalıştırılmaktadırlar.

Çalışanların, yürütülen kamu hizmetlerine göre sınıflandırılabilmesi için öncelikle kamu idarelerinin iş ve fonksiyon analizine ihtiyaç duyulur Herhangi bir hizmetin kamu hizmeti kapsamında olup olmaması ile bu hizmetin ne şekilde sunulacağının öncelikle tespit edilmesi gerekir. Kamu hizmeti kapsamında belirlenen bir hizmetin sadece kamu sektörünce sunulmasının yanı sıra özel sektör tarafından da sunulabilmesi mümkündür. Yani devlet tarafindan kamu hizmeti olarak kabul edilen ve kamu kaynaklarından finanse edilen hizmetler, kamu sektörü tarafından sunulabileceği gibi özel sektör kuruluşları tarafından da sunulabilmektedir.

Güney Kore'de ve Türkiye'de kamu görevlileri, sunulan kamu hizmetleri temelinde sınıflandırılmaktadır. Kamu görevlilerinin istihdam şekilleri de yürütülen bu hizmetler ekseninde şekillenmektedir. Bununla birlikte kamu görevlilerinin istihdam türü ve oranlarında da ülkeden ülkeye farklılıklar görülebilmektedir. Devletin asli personel istihdam şekli olan memurların diğer kamu görevlileri (işçi, sözleşmeli personel, geçici personel, vs.) ile olan oransal ilişkisi de devletlere göre değişebilmektedir. Örneğin İngiltere'de devlet memurlarının toplam kamu görevlileri içerisindeki oranı \%13'tür. 


\section{SIYASET ILE KAMU YÖNETIMININ AYRIŞTIRILMASI VE KAMU HIZMETLERININ SUNUMU İÇIN TEŞKILATLANMA}

Kamu personel yönetiminin tarihsel gelişimi ülkeden ülkeye değişiklikler göstermektedir. Ancak ülkeler arasındaki farklılıklar ile birlikte bazı hususlarda benzerliklerin yaşanması da söz konusudur. Örneğin insan kaynakları yönetiminde mevcut olan "siyasal kayırmacılık", "insan gücünden verimli bir şekilde yararlanılması" ve "insan ilişkilerine önem verilmesi" gibi genel durumlar bütün ülkelerde yaşanmaktadır (Öztekin, 1997:99).

Özel sektörde 1900'lü yılların ikinci yarısından itibaren hızla yaygınlaşan personel yönetiminden insan kaynakları yönetimine geçişin ivedilikle kendisini kamu sektöründe de göstermesi gerekmektedir. Bu bağlamda klasik personel yönetimi anlayışı ve alışkanlıklarından arınarak çağdaş yönetim tekniklerine bağlı insan kaynakları yönetimine geçiş sağlanmalıdır. Bu bağlamda kalkınma yolundaki bir ülkenin siyasi kayırmacılıktan verimliliğe odaklı bir kamu yönetimi sistemine geçmesi büyük önem taşımaktadır.

Kamu yönetiminin işleyişine yön veren üç temel ana akım mevcuttur. Bunlardan ilki; devletçi ve bürokratik bir anlayışı taşıyan, hukuk kuralları temelli geleneksel kamu yönetimi (Public Administration) yaklaşımıdır. İkincisi de 1980'li y1llardan itibaren rekabeti esas alan, etkin ve küçük devlet yaklaşımının izdüşümünde özel sektör tecrübesinin kamu kesimine aktarılmasıyla şekillenen ve performans yönetimini öne çıkaran yeni kamu yönetimi (New Public Management) anlayışıdır. Üçüncüsü ise 2000'li yıllarda çoğulculuğu ve tarafların mutabakatını esas alan ve karar alma süreçlerine paydaşların katılımını öne çıkaran Yeni Kamu Yönetişimi (New Public Governance) veya Yeni Kamu Hizmeti (New Public Service) yaklaşımıdır (Robinson, 2015:24).

Kamu yönetimi alanı, Woodrow Wilson tarafından kamu yönetimi teşkilatının siyasi alandan ayrılarak siyaset dışı bir mekanizma olarak tanımlanmıştır. Bu düşüncenin kabul görmesiyle birlikte farklı bir inceleme alanı olarak öne çıkmıştır. Bu bağlamda da kamu yönetiminin çalışma esasları, meşruiyeti, kamu yararı amacıyla hareket etmesi gibi yaklaşımlarla gelişmiştir. Max Weber'in katkısıyla ideal bürokrasi yaklaşımı sonucunda kamu yönetiminin işleyişi önemli ölçüde şekillenmiştir. Kamu yönetiminde, ideal bürokrasi kavramı çerçevesinde iş bölümü ve uzmanlaşmaya dayalı olarak, kişisellikten uzak, herhangi bir ayrıma tabi tutulmadan, tüm yazılı normlara ve ilkelere uyulması sağlanmalıdır. Bu bağlamda kamu hizmetindeki her pozisyon (kadro) için görev, yetki, hak ve sorumlulukların belirlenmesi, hiyerarşik kademelerin oluşturularak basamaklar arasındaki ast-üst ilişkilerinin düzenlenmesi gerekmektedir. Çalışanların seçiminde ve değerlendirmesinde adayların kişisel özellikleri ve performansları esas alınmalıdır. Bu noktada kamu idare ve kurumları içerisindeki "siyaset - yönetim" ayrımının sınırları yürürlüğe konacak hukuk kuralları ile belirginleştirilmelidir. Politika oluşturma ve hizmet sunum sisteminde profesyonellere ağırlık verilmesi genel kamu yönetimi yaklaşımının kilit unsurlarını oluşturmaktadır (Osborne, 2006:377-387). Bu mesele, siyasi süreçle göreve gelen kişiler ile kamu yönetiminde profesyonel olarak görev yapan kamu görevlileri arasındaki ilişkilerin belirlenmesi bakımından da önem taşımaktadır. Kamu görevlilerinin vazifelerini tarafsız, eşit, bağımsız ve ideal bir şekilde yerine getirebilmeleri için maddi ve hukuki güvencelerinin sağlanarak, özlük hakları hukuk normları ile teminat altına alınmalıdır (Rehimli, 2011:168).

$\mathrm{AB}, \mathrm{OECD}$ ve Sigma tarafindan yapılan açıklamalarda üst düzey kamu görevlisi kadrolarındaki siyasallaşma ile yolsuzluklardaki artış arasında bağ olduğu belirtilmektedir. Bu bağlamda üst düzey kamu görevlilerinin siyasi tarafsızlığına özellikle vurgu yapılmaktadır (Heywood ve Meyer-Sahling, 2008; Meyer-Sahling, 2009:26-27). Macaristan, Polonya ve Slovakya gibi ülkeler bürokrasideki üst kademeleri siyasi atamalara dönüştürmüşlerdir. $\mathrm{Bu}$ nedenle de hesap verebilirlik ve siyasi tarafsızlık bakımından sorgulanmaktadırlar (Meyer-Sahling, 2009:15). Buradan hareketle, üst düzey kamu görevlisi kadroların atanmasında siyasi etkinin sınırlandırılması ve buralara profesyonel kadrolar arasından atama yapılması ve siyasi tarafsızlığının sağlanması üzerinde durulmaktadir.

Üst düzey yöneticilerin atanmasında siyaset içi - profesyonel istihdam ayrımı ülkeden ülkeye değişiklik gösterebilmektedir. Örneğin Güney Kore'de kariyer meslekler ve kariyer-dışı meslekler olmak üzere iki temel sınıflandırma yapılmaktadır. Kariyer meslek mensupları; hakimler, savcılar, polisler, öğretmenler, diplomatik görevliler, askerler vb. olarak belirlenmiştir. Bu meslek mensupları da özel hizmetler, genel hizmetler ve teknik hizmetler olmak üzere üç başlıkta sınıflandırılmıştır. Bakanlar, Bakan Yardımcıları, seçilmiş yetkililer tarafından yürütülen siyasi hizmetler ise kariyer dışı hizmetler kapsamında değerlendirilmiştir. Bu kapsamda siyasilere, sınırlı ölçüde kendilerine yakın kişilerle çalışma imkanı sağlanmıştır. Üst düzey kamu görevlisi atamaları ise orta düzey görevliler arasından yapılmaktadır. Atamaya konu orta düzey yöneticiler, görevde yükselme sınavında başarılı olmuş ve bir atama havuzunda toplanmışlardır (Kim, 2003:15). 
Kamuda verimliliğin artırılması için siyasi kayırmacılığın azaltılması gerekmektedir. Bunun için Güney Kore, Türkiye, Fransa, İtalya, Macaristan, Yunanistan ve Belçika gibi ülkelerde kamuda ilk defa işe alınırken ülke genelinde rekabetçi bir sınav yapılmaktadır. Aday kişilerin sınavdaki başarıları işe girişlerinde esas alınmaktadır. Böylelikle eşit yarışma ve liyakat esas alınmakta, şeffaflık ön plana çıkmaktadır. Ancak eşit yarış, adalet, liyakat, şeffaflık unsurlarının gerçek anlamda varlığından bahsedilebilmesi için bu memuriyete giriş sınavlarının tüm ülkeye ve tüm kamu personeli alım süreçlerine doğrudan uygulanması gerekir. Sınav dışında ek olarak yapılacak sözlü sinav (mülakat) ve komisyon değerlendirmeleri gibi uygulamalar subjektif (öznel) değerlendirmelere neden olabileceği için siyasi kayırmacılığın yaşanmasına imkan tanıyacaktır. Bu durum yapılan mesleğe giriş sınavının etkisini önemli ölçüde ortadan kaldıracaktır.

\subsection{Kamuda İnsan Kaynakları Ofisinin Teşkilatlanması, Rolü ve Fonksiyonları}

Kamu hizmetlerinin yönetimi ve geliştirilmesi siyasi bir sorumluluktur. Buradan hareketle uygun bir şekilde örgütlenmesi ve kurumsallaştırılması gerekmektedir. AB ülkelerinde kamu insan kaynakları yönetimi alanındaki standartlaştırma ve uygulama birliği sunulacak kamu hizmeti ile ilişkilendirilerek merkezi kamu hizmeti ofisleri tarafından sağlanmaktadır. Bu kapsamdaki görev ve sorumluluklar tek bir idare tarafından yürütülebileceği gibi farklı idareler arasında da paylaştırılabilmektedir (Meyer-Sahling, 2009:26-27). Örneğin kamu insan kaynakları yönetiminden sorumlu olan ofisin görev ve sorumluluk alan1, kamuda asli olarak istihdam edilen devlet memurları ile sınırlı olabileceği gibi yine kamuda istihdam edilen tüm görevlileri de kapsayabilmektedir. Ayrıca görev ve sorumluluk paylaşımı sadece istihdam türü ile sınırlı kalmayabilir. İnsan kaynakları yönetimi ile ilgili sorumluluğun niteliği; ayrıntılı kontrol yapma, sadece standartların belirlenmesi, koşulların - ücretlerin belirlenmesi , kamu insan kaynakları bilgi sistemlerinin kurulması ve yönetimi ile işe alınacak kişilerin toplam sayılarının belirlenmesi ile de sınırlı olabilmektedir.

Tablo 2. İnsan Kaynakları Politika Merkezlerinin Kamu Yönetimi

\begin{tabular}{|c|c|c|}
\hline İnsan Kaynakları Yinetimi Bakanlığı / Ajansı & Merkezi Yönetimdeki Yeri & Ülke Örnekleri \\
\hline Merkezi Bakanlık / Ajans Yok & Melçika, İsveç \\
\hline Tek Bakanlığa / Ajans & Kamu Hizmeti / Yönetimi Ofisi & $\begin{array}{c}\text { Avustralya, Avusturya, Fransa, Norveç, Yeni } \\
\text { Zelanda, ABD, Almanya }\end{array}$ \\
\hline Tek Bakanlık / Ajans & Başbakanlık Ofisi & $\begin{array}{c}\text { Çek Cumhuriyeti, İngiltere, Polonya, Slovak } \\
\text { Cumhuriyeti, Meksika }\end{array}$ \\
\hline Tek Siyasi Konum & & \begin{tabular}{c} 
Japonya, Kore, İrlanda, Kanada, ABD, Türkiye \\
\hline Bölünmüş Otorite: Birden Fazla Bakanlık / Ajans
\end{tabular} \\
\hline
\end{tabular}

Kaynak: Lavelle, 2016:55.

Kamu hizmet ofisinin teşkilatlanması, rolü ve fonksiyonları yukarıda bahsi geçen kamu yönetimi yaklaşımları çerçevesinde ş̧ekillenmektedir. Hemen hemen tüm gelişmiş ülkelerde, insan kaynakları yönetimiyle ilgilenen merkezi bir yapı bulunmaktadır. Kamu insan kaynakları yönetiminde mevcut olan operasyonel nitelikli işler ise genellikle her kamu idaresinin bünyesinde yardımcı hizmet niteliğinde oluşturulan ve ilgili idarenin insan kaynakları yönetimine odaklanmış ofisler aracıllğıyla yürütülmektedir.

Kamu hizmetlerinin ve kamu insan kaynaklarının yönetimine ilişkin Kamu Hizmet Ofislerinin adem-i merkezi (decentralized) ve merkezi (centralized) olmak üzere iki tip örgütlenme modeli söz konusudur (Baltija, 2015:1516). Bu iki modelin avantaj ve dezavantajları aşağıdaki tabloda sunulmaktadır. 
Tablo 0. Devlet Yönetiminde İnsan Kaynakları Yönetim Sistemlerinin Avantajları ve Dezavantajları

\begin{tabular}{|c|c|c|}
\hline & Merkezi sistem & Adem-i Merkezi sistem \\
\hline $\begin{array}{c}\text { Tanım- } \\
\text { Açıklama }\end{array}$ & $\begin{array}{lcc}\text { İnsan kaynakları yönetimi politikasından } & \text { ve } \\
\text { yönetmeliklerin hazırlanması } & \text { ve } \\
\text { uygulanmasından sorumlu olan merkezi bir } \\
\text { kurum vardır. Yüksek düzeyde kontrol ve } \\
\text { standardizasyon sözkonusudur. }\end{array}$ & $\begin{array}{l}\text { Merkezi kurum esas olarak insan kaynakları yönetimi politikasını belirler, } \\
\text { bu politikaya ve yönetmeliklerin uygulanmasına başvurur, insan kaynakları } \\
\text { yönetimi politikasının uygulanmasının sonuçlarını denetler. } \\
\text { Bakanlık ve birimlerin başkanları insan kaynakları ile ilgili kararlarda daha } \\
\text { bağımsızdır. }\end{array}$ \\
\hline Avantajları & $\begin{array}{l}\text { Bakanlıklar arasında insan kaynakları yönetimini } \\
\text { uyumlaştırmak için gerekli ön koşulları sağlar. } \\
\text { İnsan kaynaklarının bütçelenmesi ve bütçe } \\
\text { harcamaları üzerinde ileri düzeyde kontrol sağlar. } \\
\text { İnsan kaynakları yönetimi maliyetleri azalır. }\end{array}$ & $\begin{array}{l}\text { Hesap verebilirlikle ilgili yetkileri belirleyen bakanlıklar, hedeflerine ve } \\
\text { işlevlerine ulaşmalarını sağlamak için insan kaynakları ile ilgili konularda } \\
\text { daha fazla karar verirler. } \\
\text { Merkezi kontrol azalır ve bu nedenle yöneticilerin insan kaynakları ile ilgili } \\
\text { kararları daha iyi benimsemelerine imkan verir. }\end{array}$ \\
\hline Dezavantajları & $\begin{array}{l}\text { Bakanlıkların taleplerine cevaplar daha yavaş } \\
\text { verilir. } \\
\text { Bakanlıkların insan kaynakları yönetiminin } \\
\text { yapısal birimlerinin çalışanları, yalnız kendi } \\
\begin{array}{l}\text { bakanlıklarının işleyişindeki rollerine } \\
\text { odaklanırlar. }\end{array}\end{array}$ & $\begin{array}{l}\text { İnsan kaynakları yönetimi politikalarının uyumlaştırılması için güçlü bir } \\
\text { kontrol ve denetim sistemi gereklidir. Merkezi yapılanmanın olmadığı ve } \\
\text { zayıf yetkilerle donatıldığı bu modelde kontrol ve denetim mümkün değildir. } \\
\text { Her bakanlık ve merkezi kurumda idari kapasite ve yeterli teknik bilgi } \\
\text { gerekir, ancak çoğunlukla bu mümkün olmadığından kamu personel } \\
\text { sisteminin işleyişinde düzensizlikler çıkar. } \\
\text { Bakanlar ve Kurum başkanlarının takdir yetkisi oldukça geniş olduğundan } \\
\text { kurumlar ve kişiler arasında ciddi maaş farklılıkları, personel alımında ve } \\
\text { personelin yükseltilmesinde usulsüzlükler sözkonusu olur. } \\
\text { Personel bilgilerinin merkezi kuruma iletilmesi için karmaşık sistemler ve } \\
\text { bunların birbiriyle uyumu için de merkezi bir müdahale gereklidir. }\end{array}$ \\
\hline
\end{tabular}

Kaynak: Baltija, 2015.

Geleneksel olarak, kamunun geneliyle ilgili insan kaynakları yönetimi ve kamu istihdamından sorumlu merkezi kamu hizmet ofisleri merkezi yönetim seviyesinde insan kaynakları yönetiminden sorumludur. Avusturya, Finlandiya, İrlanda, Japonya, Kore, Hollanda, Norveç, İsviçre, İngiltere ve ABD gibi pek çok ülkede, bu yapının daha az detaylı idari kontrol ve daha stratejik seviyedeki işlerle ilgilenme rolü bulunmaktadır (OECD, 2008:37).

Almanya'da merkezi hükümet düzeyinde insan kaynakları için merkezi bir organ bulunmamaktadır. Avustralya, Belçika, Çek Cumhuriyeti, Portekiz ve İsveç gibi bazı ülkelerde, insan kaynakları yönetiminde adem-i merkezi model sözkonusudur. Bu modelde merkezi yapı genel olarak bakanlıklar veya kurumlar arasındaki insan kaynakları yönetimini koordine etmek ile sınırlı bir görev üstlenmektedir (OECD, 2012; OECD, 2012d; OECD, 2012b; OECD, 2012).

Merkezi yapılanma modeli çerçevesinde; merkezi insan kaynakları ofisleri, bazı ülkelerde geleneksel kamu yönetimi anlayışı doğrultusunda katı merkeziyetçiliği esas alan bir niteliğe sahipken; bazı ülkelerde ise yeni kamu yönetimi yaklaşımı esas alınarak diğer idarelere operasyonel konularda yetkiler devredilmektedir. Bu bağlamda da daha çok strateji - politika seviyesinde düzenlemeler ile uygulama birliği sağlanılmasına odaklanılmaktadır.

\subsection{Kamu İnsan Kaynakları Yönetimi Reform Eğilimleri}

Son dönemde gelişmiş ülkelerde gerçekleştirilen reformlar kapsamında; insan kaynakları yönetiminden sorumlu merkezi ofislerin, genel olarak insan kaynakları yönetimi konusunda ayrıntılı merkezi kontrolleri ve diğer bürokratik işlemleri azaltıp ilke, standart ve kanuni düzenlemelerin hazırlanması, performans yönetimi, insan kaynakları bilgi sistemlerinin kurulması, strateji geliştirme, üst düzey yöneticilerin seçimi gibi insan kaynakları alanında daha özellikli hususlara odaklanma eğiliminde oldukları görülmektedir. Özellikle, kadınların ve engellilerin kamuda istihdamı, üst düzey yöneticilerin seçilmesi ve kamuda performans yönetimi konuları ön plana çıkmaktadır.

İnsan kaynakları yönetiminden sorumlu merkezi ofislerin görev ve yetkilerine ilişkin son reformlar incelendiğinde, merkezi bir kamu insan kaynakları ofisi olan Avusturya, Japonya, Kore, Norveç, İngiltere ve ABD'de sözkonusu ofislerin rol ve fonksiyonlarının özellikle yeni kamu yönetimi yaklaşımına uygun olarak yeniden yapılandırıldığı görülmektedir (OECD, 2008:38). 
Avusturya'da 2002 yılında yürürlüğe giren Deregülasyon Yasası ile birlikte insan kaynakları yönetimi merkezi organının rolü yeniden tanımlanmış ve bu organın diğer bakanlıkların insan kaynakları konusundaki kararlarına müdahalesi azaltılmıştır. Japonya'da ise Ulusal Kamu Personeli Otoritesi, stratejik personel yönetimi perspektifini esas alan çalışmalar yaparak insan kaynakları yönetiminde merkezi yapılanmanın en önemli problemlerinden biri olan artan bürokratik yazışmaları azaltmış, bürokratik prosedürleri kısaltmış, bireysel ve ayrıntılı önkontrolleri ortadan kaldırmıștır. Bu bağlamda 2002 yılında kamu hizmetinin personel yönetim sistemi ile ilgili açı standartların ortaya konulması ile birlikte onay ve görüş almaya ilişkin yaklaşık 4400 işlem ortadan kaldırılmıştır.

Kore'de merkezi kamu hizmet komisyonu; hükümet çapında işgücü yönetimi stratejisi sağlamayı, yönergeleri hazırlamayı ve bakanlıklara (ajanslar, idareler) danışmanlık hizmetleri üzerine odaklanmaktadır. Ancak atama, tazminat, çalışma koşulları dahil olmak üzere çoğu insan kaynakları alanında kontrol bazlı personel yönetimi rolünün dışına çıkmayı planlamaktadır. Norveç’te ise son yıllarda, daha fazla yetki devrine ve merkezi insan kaynakları yönetim ofisi açısından daha stratejik ve ayrıntılı olmayan bir yönetim modeline doğru bir eğilim olmuştur.

İngiltere'de merkezi insan kaynakları organının rolü yeniden gözden geçirilmiştir. İlgili organ, temelde hükümetin ilerleyen dönemde karşılaşacağı sorunlar dikkate alınarak işgücü planlaması noktasındaki önceliklerin ortaya konulması ile ilgilenmektedir. Bunun yanında, kamu üst düzey yöneticileri için potansiyel yeteneklerin ortaya çıkarılması, üst düzey kamu görevlilerinin işe alınması, kamu görevlilerinin kariyer imkanları ve profesyonel gelişimi önemli hizmet alanları arasındadır. Ayrıca kamu hizmetleri insan kaynakları ofisi, kamuda işe alma ilkeleri, kamu görevlileri ücret çetelesi, kamu görevlilerinin sosyal güvenlik hakları, işten ayrılma ve görevin gizliliğinin teminine ilişkin kural, esas ve usulleri belirlemektedir.

Amerika Birleşik Devletleri'nde ise son dönemde Personel Yönetimi Ofisi, kural koyucu rolden federal kurumlardaki inovasyon ve etkili insan kaynakları yönetimi uygulamalarının geliştiren bir niteliğe bürünmüş ve sahip olduğu görevler önemli ölçüde bütçe ofisine kaymıştır. Esnek işe alma imkanlarının kullanımı, performans değerlendirme sistemi, insan kaynaklarının stratejik yönetimi ve idarelerin hesap verebilirlik sistemlerinin geliştirilmesi konularında çeşitli teknik hizmetler sunmaktadır. Bu yeniden odaklamanın ya da rolün yeniden tanımlanması neticesinde ücret, performans yönetimi ve işe alım konuları öncelik kazanmıştır.

\section{SONUÇ}

Gelişmiş ülkelerdeki kamu insan kaynakları yönetimi alanındaki reformlar özetlendiğinde; bireysel ve ayrıntılı uygulamaların bakanlık ve kurumlara bırakıldığı, merkezi kamu hizmeti ofislerinin / kamu insan kaynakları ofislerinin ise daha stratejik seviyede insan kaynakları stratejisinin oluşturulması, yürütülecek kamu hizmetleri ekseninde iş analizlerinin ve işgücü planlarının oluşturulması, yetenekli kişilerin tespit edilmesi, üst düzey yöneticiler için sınav yapılması veya bunların belirlenmesi ve bunlar için bir havuz oluşturulması, kamuda çalışanlar için ücret, diğer mali ve sosyal haklara ilişkin çizelgelerin oluşturulması, bunların sosyal güvenlik haklarının belirlenmesi, kamuda işe alınma için genel seçim kriterlerinin ve standartların belirlenmesi ve kamu istihdamına ilişkin reformların, kanuni düzenlemelerin hazırlanması, kamu insan kaynakları bilgi sisteminin kurulması ve yönetimi ile kamuda performans yönetimi konularına odaklandıkları görülmektedir.

Azerbaycan kamu yönetiminde insan kaynaklarının yönetiminin yeniden örgütlenmesi için yapılacak çalışmalarda öncelikle kamu hizmeti, kamuda örgütlenme ve insan kaynakları konularının bir bütünlük içerisinde ele alınması gerekmektedir. Bu noktada, oluşturulacak kamu insan kaynakları yönetimi stratejisi; yapılacak işlerden sorumlu kurumlar, bu kurumların yetkili olduğu işler ve bunlara ilişkin iş süreçleri, bu işlerde çalışacak kişiler ile kendi içinde ve diğer idarelerle ilişkilerin entegre bir şekilde yürütüldügü bilgi iletişim teknolojisi sistemlerine ilişkin esasları kapsamak durumundadır. Dolayısıyla, bu kapsamdaki işleri yürütecek yapının yukarıda belirtilen konularda yetkilendirilmesi ve bu alanda yetkin kişilerden oluşması gerekmektedir. 


\section{KAYNAKÇA}

BALtiJA, Safege (2015), Report on Centres of Government in the EU Member States, ss.15-16. http://www.eupan.eu/files/repository/20150918145544_SB-ES_ZINOJ_ENG_SAFEGE.pdf (Erişim Tarihi: 03.08.2018).

EUROPEAN COMMISSION (2011), Manual On Sources And Methods For The Compilation Of COFOG Statistics: Classification Of The Functions Of Government (COFOG), Publications Office of the European, Luxembourg, ss.72-73.

HEYWOOD, Paul, Jan-Hinrik Meyer-Sahling (2008), Corruption Risks and the Management of the Ministerial Bureaucracy in Poland (Better Government in Poland Series), Ernst and Young, Warsaw, ss.15-17.

KIM, Pan Sangmook (2003), The Management of Senior Civil Servants in Korea, Yonsei University Press, KOREA, ss.15-17.

JAN-HINRIK Meyer-Sahling (2009), AB'ye Katılımdan Beş Yıl Sonra Orta ve Doğu Avrupa'da Kamu Hizmeti Reformlarının Sürdürülebilirliği, OECD/SIGMA, SIGMA. ss.26-27.

LAVELLE, John (2016), "Emerging International Trends in Human Resource Management: Implications for the African Public Sector", Human Resource Management in African Public Sector: Current State and Future Direction (Ed. Gelase Mutahaba), APS-HRMnet, UNDESA, ss.51-74.

OECD (2008), The State Of The Public Service, OECD Publishing, Paris.

OECD (2012a), Human Resources Management Contry Profiles CANADA, OECD Publishing, Paris.

OECD (2012b), "Human Resources Management Country Profiles: Czech Republic", Adolescent Psychology Around The World, OECD Publishing, Paris, ss.243-255.

OECD (2012c), Human Resources Management Country Profiles AUSTRALIA, OECD Publishing, Paris.

OECD (2012d), Human Resources Management Country Profiles BELGIUM, OECD Publishing, Paris.

OECD (2012e), Human Resources Management Country Profiles GREECE, OECD Publishing, Paris.

OECD (2012f), Human Resources Management Country Profiles ITALY, OECD Publishing, Paris.

OECD / IDB (2016), Government At A Glance: Latin America And The Caribbean 2017, OECD Publishing, Paris.

OSBORNE, Stephen (2006), "The New Public Governance?", Public Management Review, S.8(3), ss.377387.

REHIMLİ, Recep (2016), Azerbaycan Kamu Personel Yönetimi, Anadolu Üniversitesi Yayını, Eskişehir.

TUTUM, Cahit (1990), Personel Yönetimi, TODAİE Yayınları, Ankara. 